\title{
Multimodal Transport Hub - an Architectural Challenge for Smart City Bratislava
}

\author{
Pavel Nahálka, Eva Oravcová, Milan Andráš \\ Faculty of Architecture, Slovak University of Technology \\ Námestie Slobody 19, 81245 Bratislava, Slovakia \\ \{nahalka, oravcova, andras\}@fa.stuba.sk
}

\begin{abstract}
Bratislava is a part of several international and regional transport corridors. Its location it ideal for connecting different transport systems, especially rail, road, but also water, and air. As a part of the Roadmap to a Single European Transport Area Bratislava it is one of the city's network nodes of transport corridors. It is therefore necessary to become a full part of the European policy of transport transformation. As a smart city should it makes much more use of multimodal transport options, including equipment, facilities and links that will take effect in urban and architectonic image of the city. Intelligent solutions for cleaner, more efficient and safer transport, however, requires to built a significant amount of infrastructure, but also to ensure the interoperability of the various elements of multimodal transport facilities with cooperating entities, vehicles, information technology and processes. Architectural design of these tasks should also bring a higher level of satisfaction with life of inhabitants in the capital of Slovakia, especially in the transport sector. However, it is necessary that the common interest in improving transport not only looking for joint decisions as well as individuals behavior models.
\end{abstract}

Keywords: transport corridor, multimodal transport, intermodal transport, multimodal terminal

\section{Introduction}

The transport process as a set of activities linked to the movement of vehicles and moving objects (freight) and persons (passenger) is a complex organism, with considerable spatial, energetically, financial and organizational logistics needs and environmental impacts. Within the European Union is increasingly concerned with the problems of these impacts from transportation on our environment all competent authorities. A part of intentions, which are the basis for planning and 
decision-making activities, is the strategic document White Paper: Roadmap to a Single European Transport Area - Towards a competitive and efficient transport system and resource (Ref 1). The transport area is implemented, inter alia, through the priority transport links - corridors. The planning and implementation have been supported through the system and the TEN-T (Trans-European transport networks). The New EU transport infrastructure policy "will focus on financing transport narrowly defined new core network. The core network will form the thrust axis of transport in the single EU market. Its implementation will be done in the form of the creation of nine major transport corridors." Although in some cases, compared to the original plan of the White Paper, the route of these corridors does not cover Bratislava, three corridors going through our capital. It is a Baltic-Adriatic corridor, Orient / East Mediterranean Corridor and the Rhine Danube Corridor. ${ }^{1}$ The core network will connect (according lit. 3) 94 main European ports with rail and road links, 38 key airports with rail connections into major cities, $15,000 \mathrm{~km}$ of railway line upgraded to high speed, 35 cross border projects to reduce bottlenecks. Bratislava is one of the 88 urban nodes of the core network (Fig. 1).

${ }^{1}$ The Baltic-Adriatic Corridor is one of the most important trans-European road and railway axes. It connects the Baltic with the Adriatic Sea, through industrialized areas between Southern Poland (Upper Silesia), Vienna and Bratislava, the Eastern Alpine region and Northern Italy. The Orient/East-Med Corridor (Fig. 2) connects the maritime interfaces of the North, Baltic, Black and Mediterranean Seas, optimising the use of the ports concerned and the related Motorways of the Sea. Including Elbe as inland waterway, it will improve the multimodal connections between Northern Germany, the Czech Republic, the Pannonian region and Southeast Europe. The Rhine-Danube Corridor, with the Main and Danube waterway as its backbone, connects the central regions around Strasbourg and Frankfurt via Southern Germany to Vienna, Bratislava, Budapest and finally the Black Sea, with an important branch from Munich to Prague, Zilina, Kosice and the Ukrainian border. 


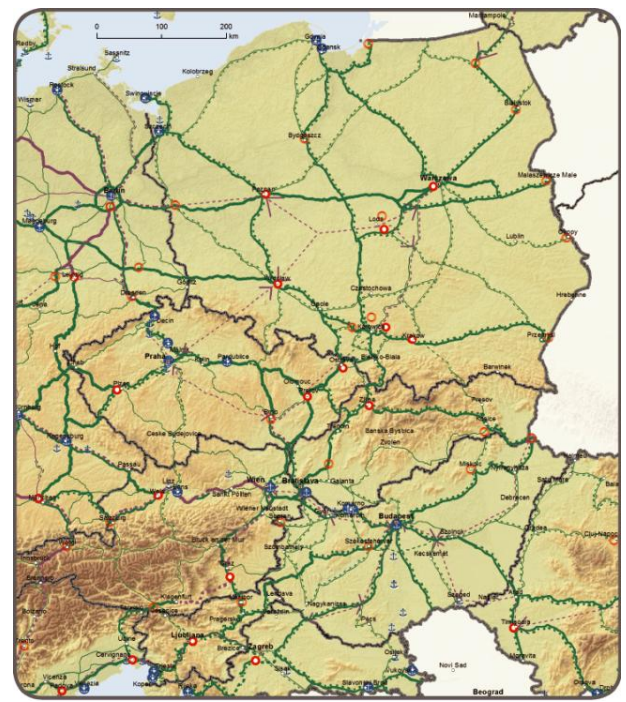

Fig.1. Comprehensive Network: Railways, ports and rail road terminals (RRT) Core Network: Railways (freight), ports and rail road terminals (RRT)

[2]

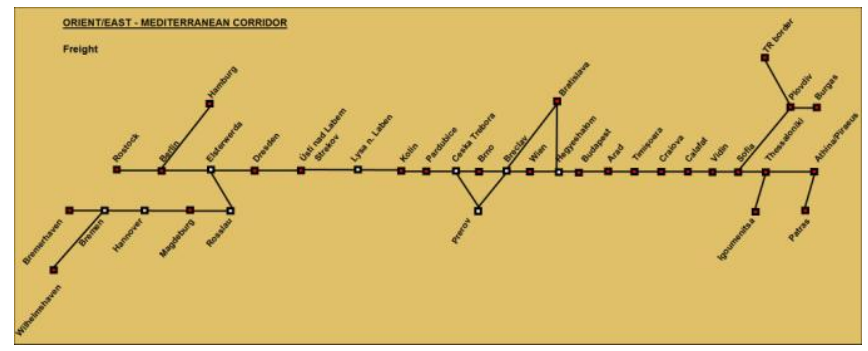

Fig. 2 Orient/East-Mediterranean Corridor, freight

A part of all actions is the pursuit of smart green solutions which showed the expected growth in freight traffic by $80 \%$ and passenger traffic by over $50 \%$, at the same time ,serving the objective, set out in the White Paper, of reducing greenhouse gas emissions from transport by $60 \%$ below 1990 levels by 2050 . The trans-European transport network must ensure efficient multi-modality in order to allow better and more sustainable modal choices to be made for passengers and freight and in order to enable large volumes to be consolidated for transfers over long distances. This will make multimodality economically more attractive for passengers, users and freight forwarders". [3, p.12]

To European planning acts are inevitably connected to the national strategies as for the Slovak Republic is The Strategic Plan for the SR transport development until 2030. This strategic document long-term nature aims to set effective direc- 
tion of development of the transport sector and determine the way of realizing its development vision. The vision of the entire transport sector in Slovakia is characterized as a "sustainable integrated multimodal transport system to meet the economic, social and environmental needs of society and contribute to the full integration of the Slovak Republic in the European Economic Area" [2, p.5]. Globally oriented economy of the Slovak Republic (mainly due to the export of goods such as cars) is necessary part of European Transport Area. Transport over long and medium distances must maximize the benefit of multimodal transport as a part of smart problem solving impact on the environment.

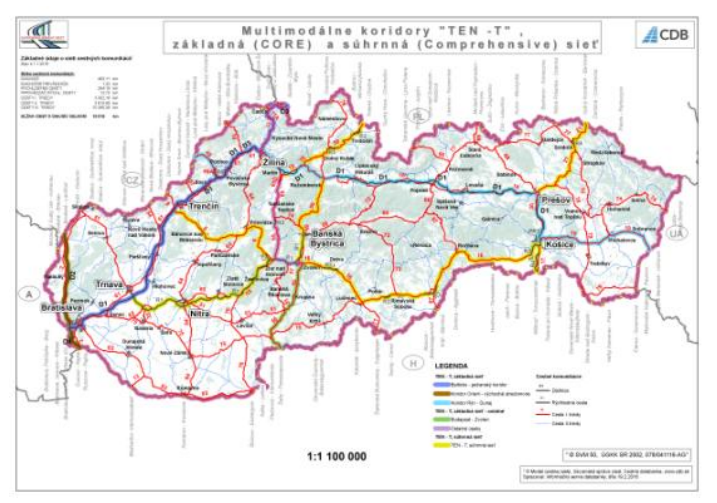

Fig. 3 The core and comprehensive network TEN-T

\section{Multimodal transport}

The multimodal transport is a combination of two or more modes of transportation of goods, such as air, road, rail, or sea, also called combined transport. For the purposes of this examination, "combined or multimodal transport" means the carriage of passengers or freight, or both, using two or more modes of transport [3, p.7], 'freight terminal' means a structure equipped for transshipment between at least two transport modes or between two different rail systems, and for temporary storage of freight, such as ports, inland ports, airports and rail-road terminals; 'urban node' means an urban area where the transport infrastructure of the transEuropean transport network, such as ports including passenger terminals, airports, railway stations, logistic platforms and freight terminals located in and around an urban area, is connected with other parts of that infrastructure and with the infrastructure for regional and local traffic [3, p.7].

Slovak Republic uses for their economic integration into the international commodity exchanges combined transport, in particular to the most efficient connection to overseas combined transport by road connections to European ports of Rotterdam, Bremen, Hamburg and the Adriatic port of Koper. According The In- 
termodal promotion center (under patronage of Ministry of Transport, construction and regional development of Slovak republic) outputs in combined transport in the years 1993 to 2015 increased in average by $15 \%$ per year. The gross tones, it is done in combined transport increased to 25 times (see Chart 1).

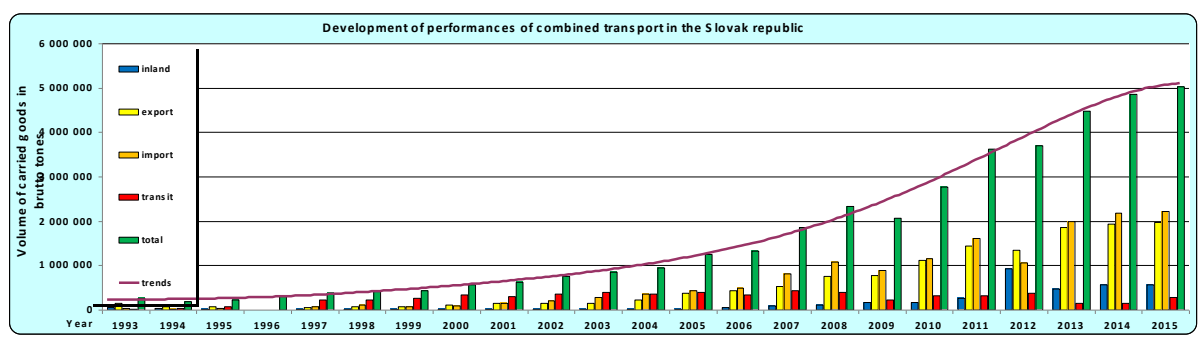

Chart 1 Long-term development of intermodal transport volumes in the SR (Volume of carried goods through intermodal transport in SR in years 1993 - 2015)

The combined transport operations Slovakia is involved mainly the next intermodal terminals, respectively container terminal: Dunajska Streda, Bratislava Pálenisko, Sládkovičovo, Žilina, right, UNS Bratislava and Kosice. Their position on the network of cooperation in the transport of V4 is shown in the attached map.

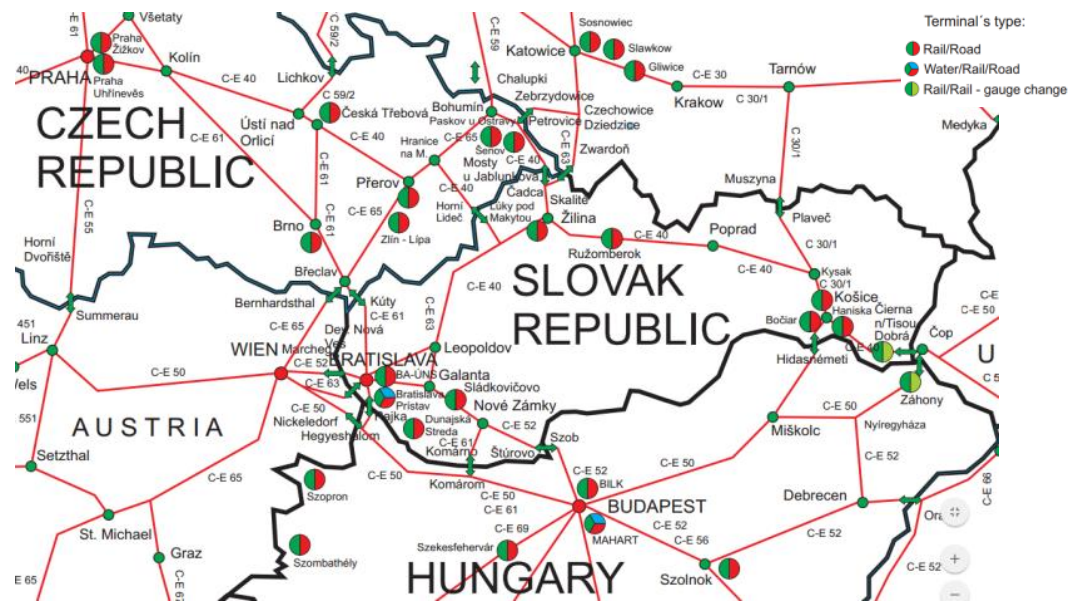

Fig. 4 AGTC network of V4 countries with connection on neighbor states

Despite the gradual increase in volumes transported in combined transport, it is obvious that Bratislava has large reserves mainly in the use of a unique position to combine the four basic modes of transport, including aviation and in particular the ship. The current status of the port transshipment does not meet the requirements of operational practices terminal. Reloading is equipped with devices for handling with only $20 \mathrm{ft}$ ISO containers, which does not allow handling all cargo units, 
which are commonly used in intermodal transport. The level of technical equipment and services is not compatible with modern intermodal transport terminals in other EU countries. Manipulative rails amounts to about only half of the required length, which does not allow the handling of integrated intermodal transport trains by the railway line. The greatest shortcoming is the limited size of the storage space, which cannot expand in that area. Serious deficiency is the private ownership relation to the port. On the agenda is getting the topic construction of a new multimodal terminal.

\section{Multimodal terminal}

The problem of construction of multimodal terminal in the Bratislava region requires a deeper analysis. Until now considered the construction of the terminal with railway, road and water transport. The strategic location of the capital city in the heart of Europe however is shaping integrate into the infrastructure and air and possibly broad gauge traffic. Within $100 \mathrm{~km}$, a distance which is efficient scale automobile road transport, there are two airports (Bratislava and Schwechat). Provided the extension, they could also serve as air freight transport. The place of construction could choose brownfield territory of Slovnaft, near which in October 2016 started construction city highway (R7 and D4 Jarovce - Ivanka on the Danube). There is also space for further development of port infrastructure, and therefore the two airports are connected to the highway and shipping network. This would enable for a smooth transition mainly container shipments into and out of a multimodal terminal. The existing railway siding in the Slovnaft area allows seamless a connection to a possible broad gauge railway line.

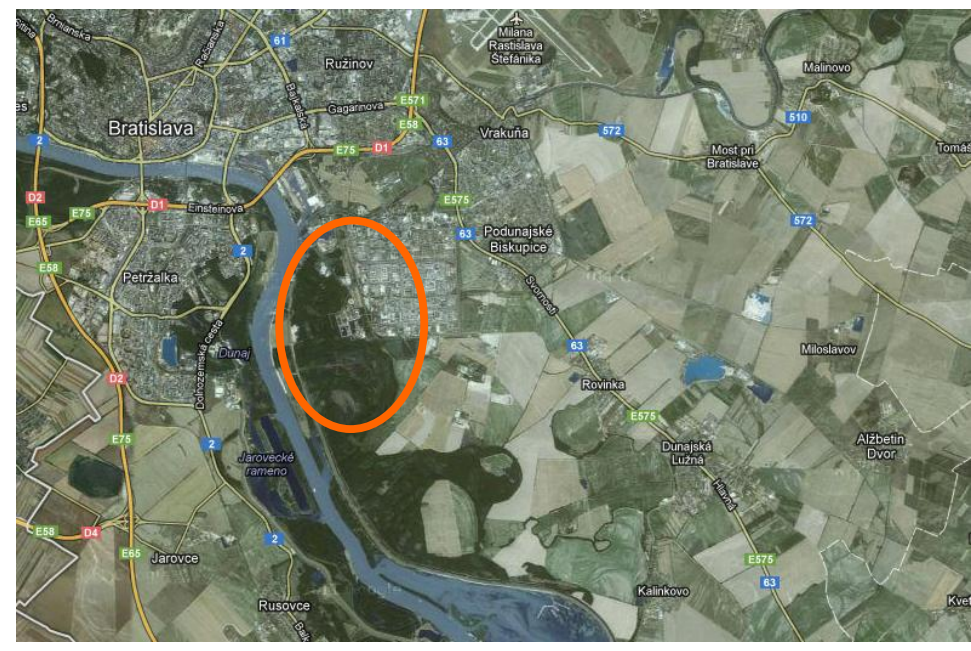

Fig. 5: One of the possibilities for future multimodal terminals located 
In forming a new multimodal terminal would be a mistake if the function was focused only on transshipment or at the free storage transport units. To intent the construction is necessary to include the construction of cross-dock centers along with logistical centers as an integral part of the area, utilizing its activities range of intelligent solutions. This could create efficient logistics and distribution complex for multimodal transport as well as for the supply of capital, as in other major European cities.

\section{The urban aspects of a multimodal terminal in Bratislava}

If the Slovak Republic wants to meet EU requirements on the issue of construction of multimodal terminals as urban node within the meaning of the technical requirements of the $\mathrm{EU}$, it must ensure conditions for construction in the spirit of the regulations of the European Parliament of September 2010 mainly in the following key points:

Interlinking rail, road, water and air freight,

- Seamless connection between the infrastructure of a comprehensive multimodal transport and infrastructure for regional and local traffic, including logistic consolidation and distribution centers,

- Bypassing urban areas for road transport to facilitate long distance traffic flows on the comprehensive network of multimodal transport,

- $\quad$ Bypassing urban areas, in the case of rail freight,

- $\quad$ Support for urban freight transport with low noise and low-carbon

- Ensure the provision of services to all freight operators nondiscriminatory way and apply transparent charges [5]

\section{The possibilities of combined transportation transit systems}

Multimodal terminal can use various combined transport transmission systems. In the case of unaccompanied traffic when containers swap bodies and road trailers are transported by road vehicles to the terminal where they are translated using cranes (vertical reloading). The main part of the carriage is then carried by train or boat. In the case of accompanied transport road vehicles using the ramp through a horizontal transshipment loaded on special low-floor wagons or in the ship.

Vertical transshipment in multimodal terminals situated in the port most frequently performed loading cargo unit port or ship crane on a ship (the system LO-LO). Horizontal transshipment road vehicles most often represents the RO system - RO (Roll on - Roll off), or system-RO-LA (Rollende Landstrasse, rolling road), which is the carriage of goods vehicles and road trains on flat wagons with 
low floor with a portable ramp. In cases bimodal transport from car to rail is also used for horizontal transport system roll-off container system ACTS (Abroll Container Transport System) - road vehicle is equipped with a manipulator, so in addition to the transport of a standard roll-off container also allows the handler to the railway basket car with three revolving frames for containers.
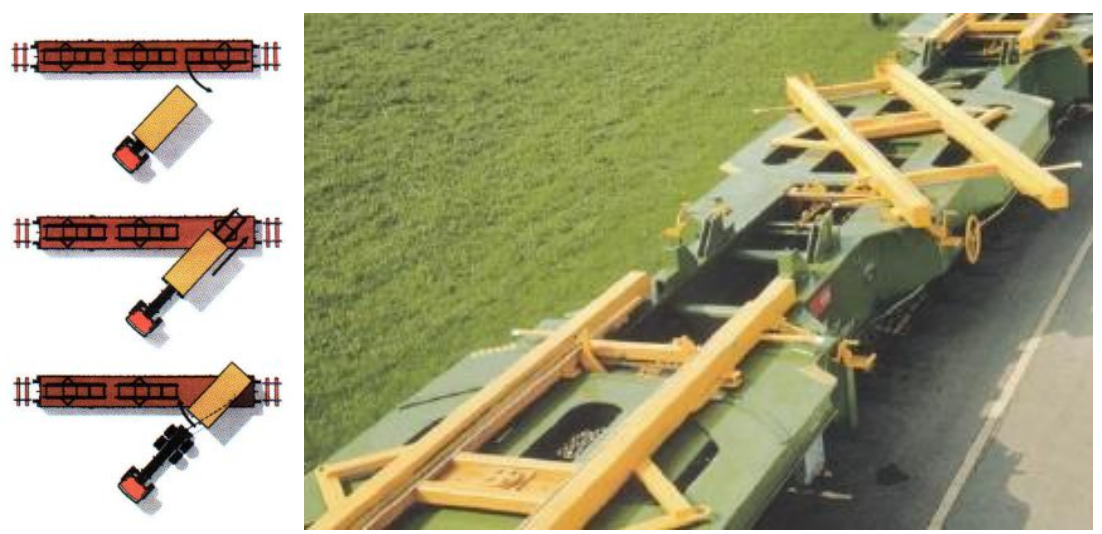

Fig. 6: roll-off container system ACTS

\section{Architectural specifications of a multimodal terminal}

If the new multimodal terminal meets European criteria dispositional and operational solutions and suitable equipment, then the solution should meet the following parameters:

- Length of railway tracks for loading and unloading should be at least $750 \mathrm{~m}$

- River wharf length should be at least $110 \mathrm{~m}$

- The depth of the dive dock should be at least 2.80 to 3.50 Underground

- Handling equipment should be able to move all the cargo units that are commonly used in intermodal transport - must comply with EU requirements for load bearing capacity of 45 tons on the hinge [6]

- Handling equipment should be one hundred percent reserve,

- Reloading and loading should be automated as far as possible,

- Terminal capacity (number of railway tracks, as well as the number of trips) should be chosen so that a comprehensive multimodal transport train, or river vessel can be processed in one hour and road trucks for distribution did not wait longer than 20 minutes

- System for road trains RO / LA is a need to establish a separate railroad track with ramp 
- System for road trains RO / RO needs to be built dock with a ramp,

- Terminal solution conceived with maximum respect for the environment

\section{Multimodal terminal space required of functional units}

Comprehensive multimodal terminal must at least consist of the following functional units:

- Feeder road to the terminal entrance and exit points for road vehicles (gate), internal road network, storage and parking areas

- Track handling equipment (cranes and lift trucks)

- Transshipment tracks, connecting the rail with a rail network

- Service facilities, office buildings, parking for staff

- Dock for boats

- Cross-dock center

- logistics center

- Distribution center [7]

In 2010, study for a public terminal of intermodal transportation Bratislava in order to eliminate the shortcomings of the current port. They are:

- insufficient length transshipment tracks

- poor handling means in terms of their number, acceptability, handling speed and the possibility to manipulate all of the intermodal transport unit (ITU) Containers, swap bodies and manipulable Trailers,

- Lack of storage space in the range of handling equipment, requiring an increased number of operations of the IPU.

The study suggests trimodal part of a terminal in length min. $300 \mathrm{~m} 3$ boats "Danube Europe II", and it paved the port at the edge of the pool Pálenisko, bimodal part in the sequel trimodality of up to $450 \mathrm{~m}$ so that the total usable length under the crane track was $750 \mathrm{~m}$. [8]

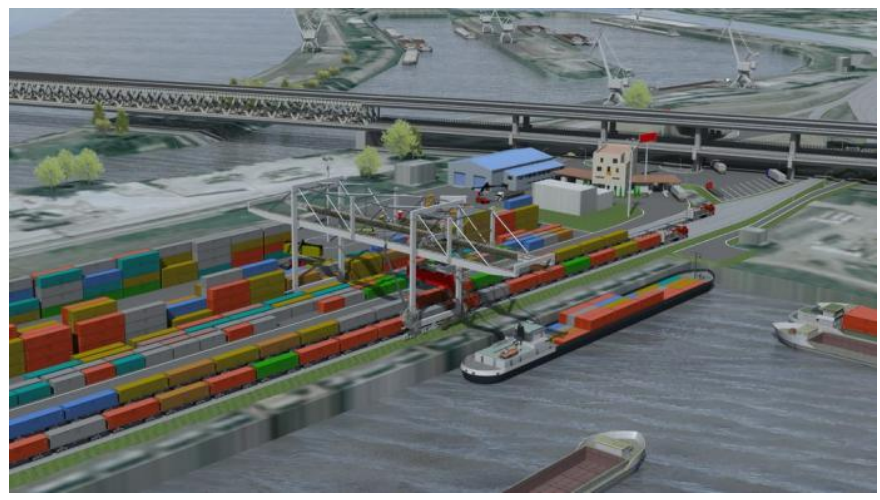

Fig. 7: Public terminal of intermodal transport Bratislava- Pálenisko, study [8] 


\section{Conclusion}

Multimodal terminal in Bratislava with regard to the strategic geographical position can serve as a link between the North Sea-Baltic ports and the Mediterranean-Adriatic port as well as a bridgehead in Ukraine, Russia and further east to China. Therefore, the conceptual design and technical installations must be made by the competent authorities to give due attention. Smart solutions that allow reducing the burden of freight transportation in the area of the city should bring significant environmental benefits.

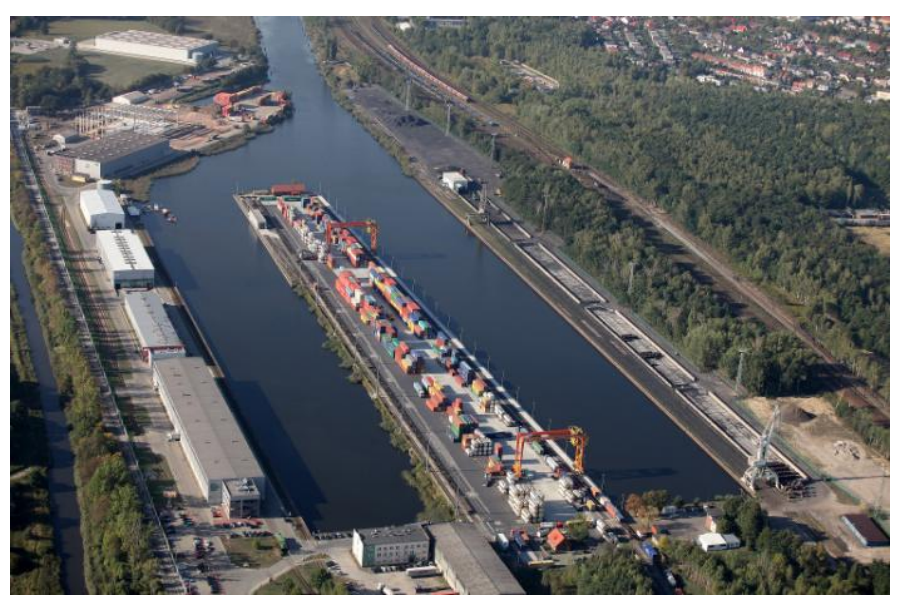

Fig. 7: Multimodal terminal Śląskie Centrum Logistyki SA, Gliwice, Poland

[9]

An obvious part of such solutions, however, the planning, construction and management of infrastructure within multimodal transport system as in freight as well as passenger transport. Planning and decision-making processes cannot be focused on the ephemeral short-term projects, but must be geared towards longterm and sustainable solution even at the cost of higher invested funds at present. Absolute priority should be the implementation of such solutions, such as multimodal terminal in Bratislava in such parameters that will be sufficient at a remote time horizon with a new understanding of the role of smart city Bratislava as an urban node of core network at the crossroads of the main transport corridors of the EU. 


\section{References}

1. WHITE PAPER, Roadmap to a Single European Transport Area - Towards a competitive and resource efficient transport system, Brussels, 28.3.2011 COM (2011) 144 final, pp 30

2. Bado J., e a.: VUD 126 / 2015, 1218/A301/2015, Strategic Development Plan of the SR transport by 2030 , phase II, Report on the Evaluation of the strategic document, 14th September 2016, pp 275

3. European Commission MEMO-14-525_EN, Brussels, 11th September 2014, New EU transport infrastructure policy - background, pp 8

4. http://www.businessdictionary.com/definition/intermodal.html (October 2016)

5. http://eur-lex.europa.eu/LexUriServ/LexUriServ.do?uri=COM:2011:0658:FIN:SK:PDF (October 2016)

6. http:// www.intermodal-terminals.eu (October 2016)

7. http://sk.wikipedia.org/wiki/Termin $\% \mathrm{C} 3 \% \mathrm{~A} 11$ kombinovanej_dopravy (October 2016)

8. http://www.asb.sk/inzinierske-stavby/zeleznica/verejne-terminaly-intermodalnejprepravy-bratislava-aleopoldov-priprava-projektu (October 2016)

9. http://www.scl.com.pl/ (October 2016) 